\title{
PHOTOGRAMMETRIC MAPPING USING UNMANNED AERIAL VEHICLE
}

\author{
N. Graça ${ }^{a}$, E. Mitishita ${ }^{a}$, J. Gonçalves ${ }^{\text {b }}$ \\ ${ }^{a}$ Programa de Pós-Graduação em Ciências Geodésicas - UFPR (mitishita@ufpr.br); (niarkiosnl@ hotmail.com) \\ ${ }^{\mathrm{b}}$ Instituto Tecnológico Simepar/ PPGERHA (jgoncalv@simepar.br)
}

KEY WORDS: UAV, Photogrammetry, Photogrammetric Mapping, Direct Georeferencing.

\begin{abstract}
:
Nowadays Unmanned Aerial Vehicle (UAV) technology has attracted attention for aerial photogrammetric mapping. The low cost and the feasibility to automatic flight along commanded waypoints can be considered as the main advantages of this technology in photogrammetric applications. Using GNSS/INS technologies the images are taken at the planned position of the exposure station and the exterior orientation parameters (position Xo, Yo, Zo and attitude $\omega, \varphi, \chi$ ) of images can be direct determined. However, common UAVs (off-the-shelf) do not replace the traditional aircraft platform. Overall, the main shortcomings are related to: difficulties to obtain the authorization to perform the flight in urban and rural areas, platform stability, safety flight, stability of the image block configuration, high number of the images and inaccuracies of the direct determination of the exterior orientation parameters of the images. In this paper are shown the obtained results from the project photogrammetric mapping using aerial images from the SIMEPAR UAV system. The PIPER J3 UAV Hydro aircraft was used. It has a micro pilot MP2128g. The system is fully integrated with 3-axis gyros/accelerometers, GPS, pressure altimeter, pressure airspeed sensors. A Sony Cyber-shot DSC-W300 was calibrated and used to get the image block. The flight height was close to $400 \mathrm{~m}$, resulting GSD near to $0.10 \mathrm{~m}$. The state of the art of the used technology, methodologies and the obtained results are shown and discussed. Finally advantages/shortcomings found in the study and main conclusions are presented.
\end{abstract}

\section{INTRODUCTION}

The use of high resolution images from unmanned aerial vehicles (UAVs) to extract metric information of the Earth`s surface has been widely researched in the last years. Operational advantages such as autonomous flight, lower costs for the photogrammetric system and flight mission are the main attractive for the use of this new technology in photogrammetric applications. However, due to flight regulations most UAV applications are in research domain. Currently, only a small number of mapping projects have used the UAV Technologies. The use of UAVs in Photogrammetry is currently being developed and most knowledge comes from results published by the main research centres around the world. Colomina $\&$ Molina (2014) show the evolution and the state of the art of Unmanned Aerial Systems (UAS) in the field of Photogrammetry and Remote Sensing emphasising on regulations, acquisition systems, navigation and orientation.

Off-the-shelf UAV systems are frequently studied for photogrammetric applications. For this UAV types, many difficulties arise, for instance, the image's forward overlap along the flight line and sidelap for adjacent flight lines are commonly not correct due to the platform instability during the flight; the inaccuracies of the direct measurement of the imaging sensor (position and orientation) due to the use of a compact and low cost Inertial Measurement Unit (IMU); elevated number of images due to the use of compact and low cost digital cameras and low flying height. The regulations for UAV flights, flight security proceedings and approval for flight mission, especially on urban areas are important matters not yet completely defined and solved in many countries. Despite the autonomous characteristic of the UAV photogrammetric flight capable to take images in 3D spatial positions previously planned, the flight mission requires qualified pilot for take-off and landing operations.
Considering the UAV facilities to perform the flight missions, one may state that the applicability of this technology is more suitable for engineering projects that need up-to-date information of the earth's surface, where the high spatial resolution images are necessary for frequent evaluations. Studies about UAV use for environmental monitoring, land slide, open pit mine mapping, urban cadastre and remote sensing are described by Everaerts, 2008; Eisenbeiss, 2009 and Eisenbeiss, 2011. Jorge et al., (2011) present a study of the use of UAV for precise agriculture. Monitoring of environment impacts are presented by Longhitano, 2010. Darwin et al., (2013) showed a study that was performed to use UAV technologies to acquire images for simulation models at low altitude. The UAV was equipped with a calibrated digital camera and the autopilot system. The images were used to perform a study to obtain the DTM and orthoimages. The obtained results showed that UAV technologies have great potential to acquire such products. Other studies of a less common use of UAVs on remote sensing are presented by Laliberte et al., 2011, Turner et al., 2012 and Khan et al., 2012.

This paper shows a study of an UAV system used to acquire aerial images to generate orthoimages of a rural area, containing a small town. The main phases of work were subdivided into Photogrammetric flight mission, control and check points surveying, aerial triangulation, Digital Terrain Model (DTM) and orthoimage generation. The obtained results in each phase are presented and discussed.

\section{PHOTOGRAMMETRIC FLIGHT MISSION}

The photogrammetric system UAV SIMEPAR was used to acquire the images for a block. This system uses a PIPER J3 UAV HYDRO AIRCRAFT (Figure 1) with the following characteristics: wingspan of 2.8 meters; length of 1.8 meters; weight $9.5 \mathrm{~kg}$; payload of $3.0 \mathrm{~kg}$; engine: DLE $30 \mathrm{cc}$ (aviation gas); autonomous flight of 60 minutes; average speed of $70 \mathrm{~km} /$ 
hour. The system is equipped with a "micropilot MP2128g" GPS / INS integrated to provide the aircraft position and orientation parameters at the instant the images are taken. A Sony Cyber-shot ${ }^{\circledR}$ DSC-W300 was fixed on the platform and connected with the micropilot system to get the aerial images autonomously. The camera has a CCD sensor with 4224 x 3168 pixels. The pixel resolution is equal to $0.002 \mathrm{~mm}$ and the nominal focal distance equal to $7.6 \mathrm{~mm}$. The camera calibration was performed to obtain the interior orientation parameters used in the photogrammetric procedures. The obtained results are shown in Table 1.

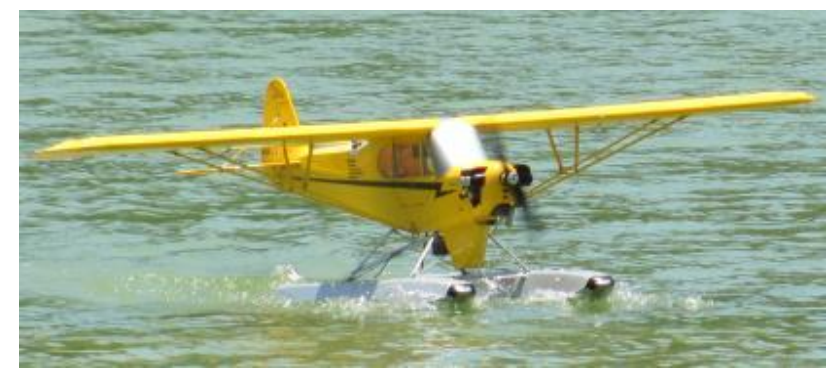

Figure 1- UAV platform - PIPIR J3 HYDRO AIRCRAFT

\begin{tabular}{c|c|c|c}
\hline \multicolumn{4}{|c}{ Interior orientation Parameters (IOP) } \\
\hline Parameter & Value $(\mathrm{mm})$ & Parameter & Value \\
\hline $\mathrm{c}$ & 8.123 & $\mathrm{~K}_{1}$ & $-9.45364 \mathrm{e}-04 \mathrm{~mm}-2$ \\
\hline$\sigma$ & 0.003 & $\sigma$ & $6.39913 \mathrm{e}-05 \mathrm{~mm}-2$ \\
\hline xo & 0.052 & $\mathrm{~K}_{2}$ & $-7.03656 \mathrm{e}-05 \mathrm{~mm}-4$ \\
\hline$\sigma$ & 0.003 & $\sigma$ & $6.59402 \mathrm{e}-06 \mathrm{~mm}-4$ \\
\hline yo & 0.127 & $\mathrm{~K}_{3}$ & $1.14873 \mathrm{e}-06 \mathrm{~mm}-6$ \\
\hline$\sigma$ & 0.003 & $\sigma$ & $2.12248 \mathrm{e}-07 \mathrm{~mm}-6$ \\
\hline \multirow{3}{*}{$\sigma$} & $\mathrm{P}_{1}$ & $2.31433 \mathrm{e}-04 \mathrm{~mm}-1$ \\
\cline { 3 - 4 } & $\sigma$ & $1.28104 \mathrm{e}-05 \mathrm{~mm}-1$ \\
\cline { 3 - 4 } & & $\mathrm{P}_{2}$ & $4.23658 \mathrm{e}-04 \mathrm{~mm}-1$ \\
\cline { 3 - 4 } & & $\sigma$ & $1.07574 \mathrm{e}-05 \mathrm{~mm}-1$ \\
\cline { 3 - 4 }
\end{tabular}

Table 1- Interior orientation parameters determined by camera calibration

The photogrammetric block used in this study has four strips (approximately 10 photos per strip). The used mean flying height was approximately 450 meters, resulting on a Ground Sample distance (GSD) of approximately $0.10 \mathrm{~m}$. The planned forward and side overlaps were approximately $60 \%$ and $40 \%$ respectively. The planned and achieved images positions are shown in Figure 2. Yellow Points are the planned location for images stations. The blue lines are the performed tracks. Due to strong wind there was a significant displacement from the planned flight lines positions.

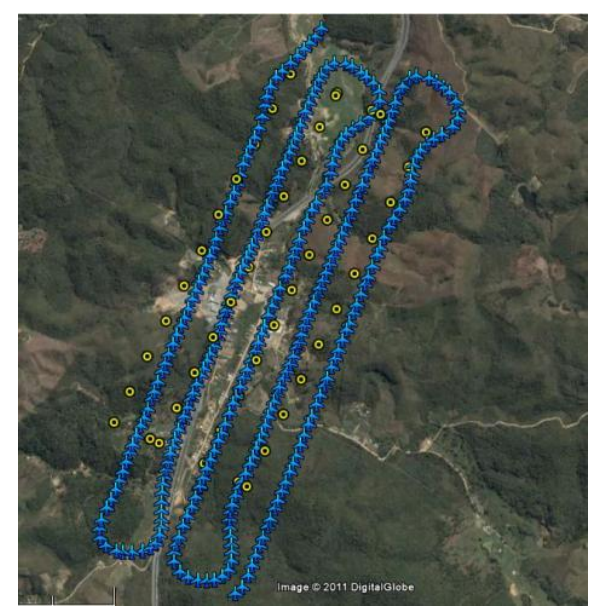

Figure 2- The planned (yellow dots) versus the realized photogrammetric coverage

A small block with 30 images was extracted from the whole block to perform the proposed study. Due to overlap gaps between photos in some strips an additional strip was added in the block. This strip was gotten when the aircraft was returning to the base (landing). Figure 3 shows the block layout with images and strips used in the study. Figure 4 shows one of the images in the block.

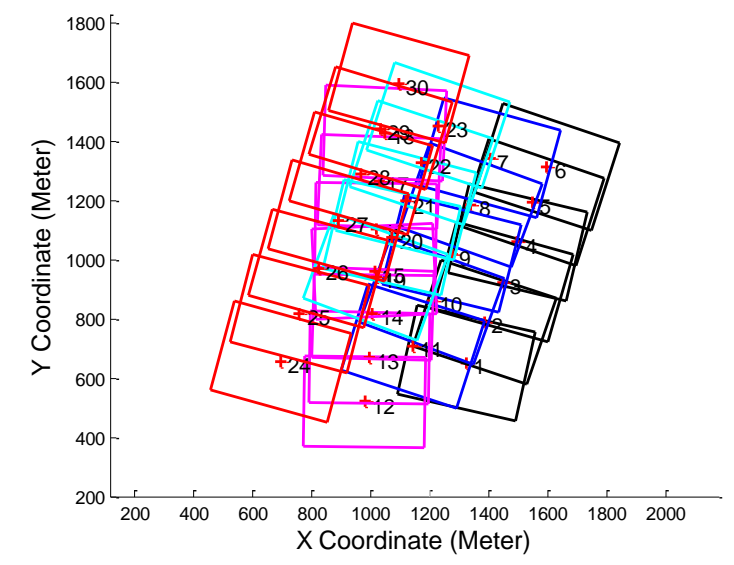

Figure 3- Block Layout used in this study

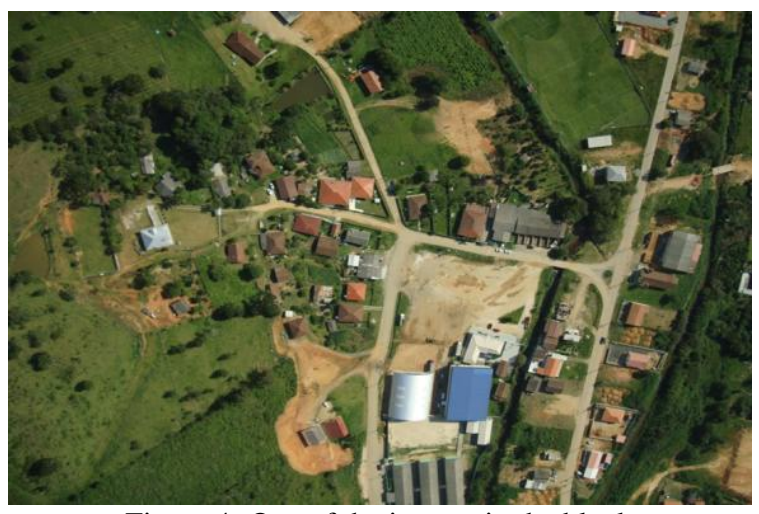

Figure 4- One of the images in the block 


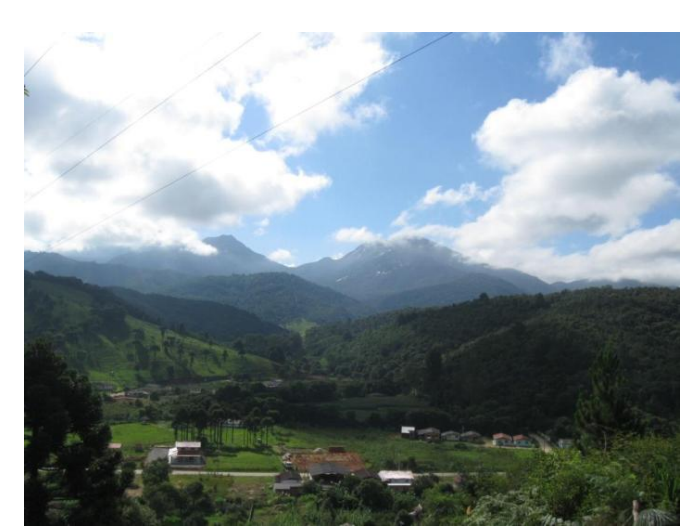

Figure 5- Landscape view of the coverage region

\section{AERIAL TRIANGULATION}

The conventional aerial triangulation (bundle adjustment) was performed for the indirect determination of the exterior orientation parameters (EOP) of the image block. The exterior orientation parameters, obtained directly by GPS/INS (micropilot MP2128g) system integration for autonomous flight, were not used in the aerial triangulation due to inaccuracy of the obtained values. According to Colomina \& Molina (2014) even though the low cost UAV have GNSS/INS system for automatic navigation, the direct measurements of the sensor' position and orientation are seldom used due to the performance limitations of current miniature IMUs. The LPS (Leica Photogrammetry Suite) software was used to measure the photogrammetric tie points, control and check points. The tie points were located close to "Von gluber" position yielding 3 to 6 redundancy measurements. All measurements were performed by manual operations using monocular view. Twelve control points and 12 check points were placed in the block. The Figure 6 shows the approximate locations of the photogrammetric points used in the block. The bundle adjustment was executed in the LPS software. The main obtained results are shown in Table 2.

\begin{tabular}{|c|c|c|}
\hline \multicolumn{3}{|c|}{ Image coordinates residuals } \\
\hline Rmse $x=0.0$ & $4 \mathrm{~mm}$ & $\mathrm{mse} y=0.004 \mathrm{~mm}$ \\
\hline \multicolumn{3}{|c|}{ Control points coordinate residuals (m) } \\
\hline Rmse $X=0.154$ & Rmse $Y=0.164$ & Rmse $\mathrm{Z}=0.364$ \\
\hline \multicolumn{3}{|c|}{ Check point discrepancies $(\mathrm{m})$} \\
\hline Mean DX $=0.065$ & Mean DY $=-0.023$ & Mean DZ $=-0.206$ \\
\hline Rmse DX=0.344 & Rmse DY=0.332 & Rmse DZ $=0.571$ \\
\hline $\begin{array}{l}\text { Rmse }=\text { Root Mean } \\
\text { DX, DY, DZ = X,Y, }\end{array}$ & $\begin{array}{l}\text { uare Error } \\
\text { discrepancies }\end{array}$ & \\
\hline
\end{tabular}

Table 2 - Main results of the residuals from the bundle adjustment aerial triangulation

The results of the root mean square errors of the measurement's residuals, reported in Table 2, confirm that the obtained precision values from bundle adjustment yielded to acceptable values. The RMSE in image measurements are close to two image pixel. The RMSE in horizontal coordinates of the control points are close to $0.22 \mathrm{~m}$ (two pixels on the ground). Considering the vertical precision of $3 \mathrm{D}$ point intersection, which is computed by the average value of photogrammetric base, focal length and error measures in homologous points (equal to two pixels), the RMSE of $\mathrm{Z}$ coordinate is lower than the expected value $(0.60 \mathrm{~m})$. The block's accuracies analysis, based on the average value and mean square errors of check point's discrepancies showed that the horizontal accuracy of the block reached a magnitude of five pixels on the ground $(0.48 \mathrm{~m})$ and the vertical accuracy is acceptable when compared to expected value for the intersection. The lack of control points on the block's border, as can be seen in Figure 6, should be the probable cause of the horizontal accuracy of the block is lower the expected value of two pixels.

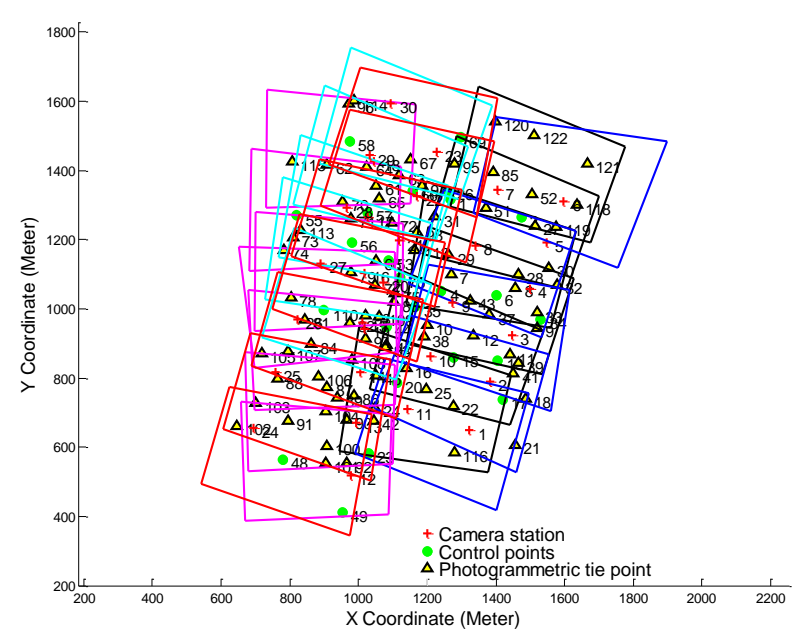

Figure 6 - configuration of control and tie points on the block

Comparing the graphics of the image blocks shown in Figures 3 and 6 , it's possible to identify different overlapping between photos and strips. In Figure 03, the image's orientation angle's values in the $\mathrm{X}$ and $\mathrm{Y}$ axes (Omega and phi) were assumed to be equal to zero. In Figure 06, the image's orientation values that were computed in the bundle adjustment were considered. These results show images with high vertical displacement above to tolerable values, caused by the platform instability, due to atmospheric variations at the time of flight. Similar results were obtained in Gülch, (2012). In his study of the use of fixed wing UAV in photogrammetric procedures, concluded that the external flight conditions do influence images overlaps.

\section{DIGITAL TERRAIN MODEL}

The triangulated Digital Surface Model (DSM) of the block region was obtained by photogrammetric procedures using digital correlation of pixels in the LPS software. It was adopted a correlation matrix of $7 \times 7$ dimension and a threshold correlation coefficient equal to 0.8 . The procedure to select only ground points to generate the Digital Terrain Model (DTM) was done based on the stereoscopic view and manual procedures. The number ground points selected to generate the DTM was nearly to 70258 (about 1 point per square meter). The DTM region has the lowest altitude close to $782 \mathrm{~m}$ and $866 \mathrm{~m}$ for the highest value. Based on height values of the 24 surveyed control points, the accuracy for the DTM was approximately to $1.6 \mathrm{~m}$. Figure 7 shows the 3D representation of DTM region. 


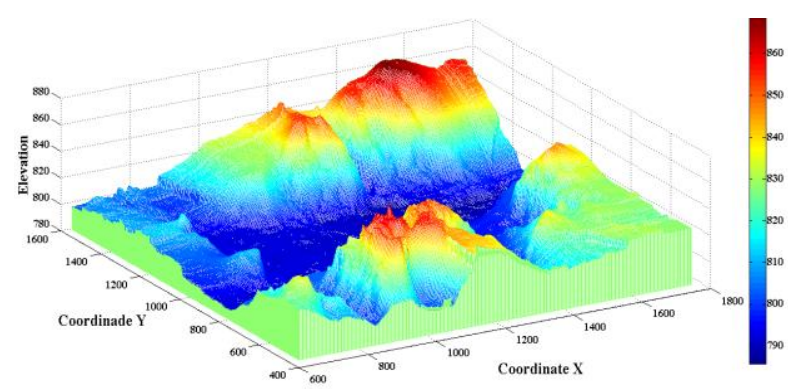

Figure 7 - Show the 3D representation of the generated DTM

\section{ORTOIMAGE GENERATION}

The LPS software was also used to generate the orthoimages. For this step the basic requirements are the digital image, the interior and exterior orientation parameters of each image and the DTM of the study area. The orthoimages were generated using image resolution equal to one GSD $(0.10 \mathrm{~m})$. Figure 8 shows one of the generated orthoimages.

Ten individual orthoimages were connected automatically using mosaicking procedures in LPS software. The whole orthoimage of the study area is shown in Figure 9.

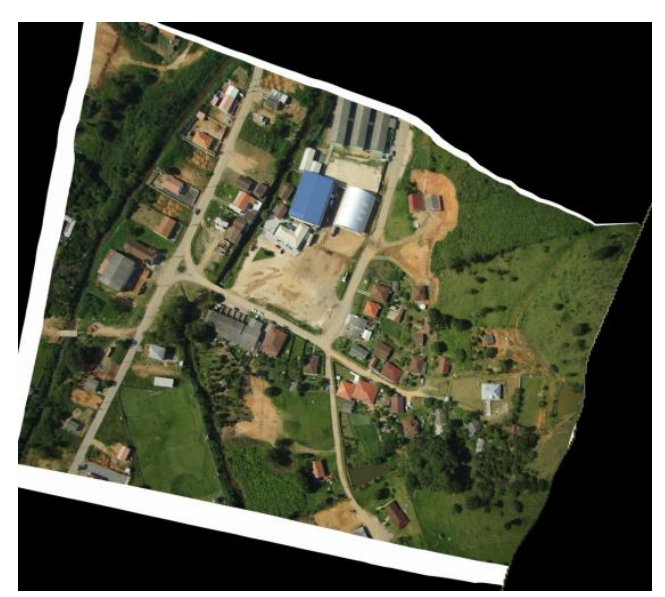

Figure 8 - One of the generated orthoimages

The horizontal accuracy of the final orthoimage was performed by the analysis of the planimetric discrepancies from 12 checkpoints. The resulted values of the root mean square error (RMSE) of the discrepancies in the $\mathrm{X}$ and $\mathrm{Y}$ coordinates were respectively $0.316 \mathrm{~m}$ and $0.327 \mathrm{~m}$, resulting on a horizontal accuracy of $0.455 \mathrm{~m}$. The individual values of each planimetric discrepancy are shown in Figure 10. As it was expected, the horizontal accuracy of the final orthoimage is approximately equal to value that was obtained in the aerial triangulation procedure.

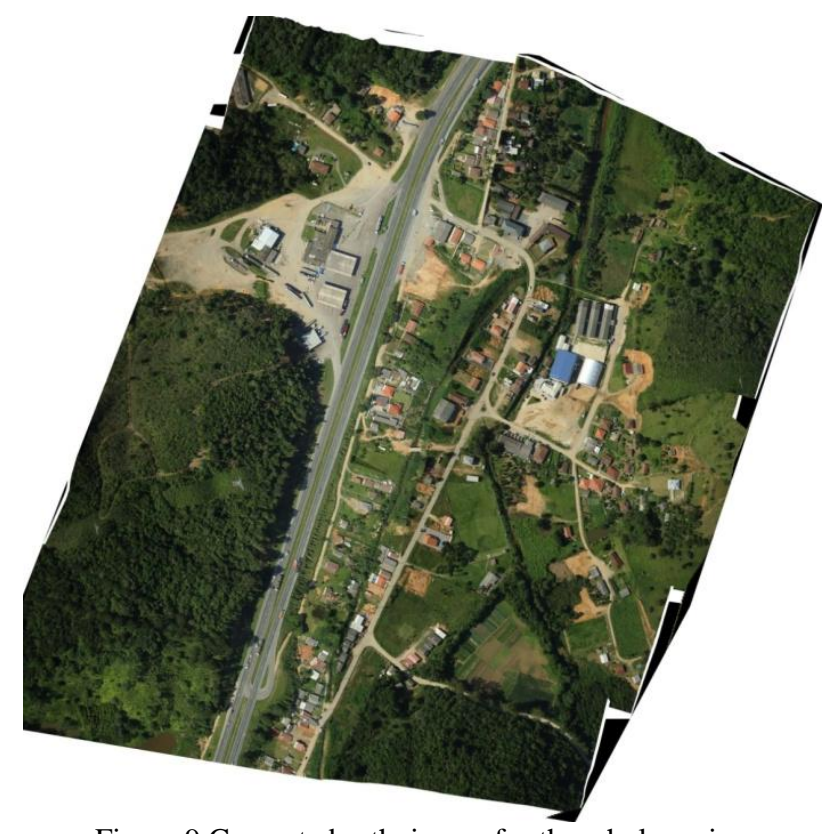

Figure 9 Generated orthoimage for the whole region

\section{CONCLUSIONS AND RECOMMENDATIONS}

This paper shows and discusses the obtained results from the conducted study to generated conventional orthoimages using the UAV-SIMEPAR photogrammetric system. The study area is a rural region with a small village in a valley. The photogrammetric flight was performed with a flight height nearly to $440 \mathrm{~m}$. Using a Sony Cyber-shot ${ }^{\circledR}$ DSC-W300, the digital images were automatically taken. The images have a pixel resolution equal to $0.002 \mathrm{~mm}$, resulting on a Ground Spatial Resolution approximately to $0.10 \mathrm{~m}$. The aerial triangulation, DTM and orthoimage generations were the work phases performed. Considering the obtained results from the work phases, the main conclusions can be drawn:

- Using a common UAV system, the geometric characteristics of photogrammetric flight can vary significantly from what it was planned. The platform instability due to atmospheric variations at the moment of the flight can cause significant variation in the area covered by the image, forward and sidelap overlaps;

- The direct measurement of the image's exterior orientation parameters via the Micropilot system did not achieve the required accuracies to minimize the number of control points in the aerial triangulation process;

- From the analysis of checkpoints discrepancies, the performed bundle adjustment achieved horizontal accuracy close to $0.48 \mathrm{~m}$. This accuracy is lower than the expected value of two pixels on the ground $(0.20 \mathrm{~m})$. The most likely cause for this inaccuracy is the deficiency of control points on the block`s border, caused by the impossibility to find recognizable photogrammetric details in the region of dense forest;

- The aerial triangulation procedure yielded acceptable vertical accuracy, considering the expectable value equal to 0.60 . This value is computed by the relationship between the photogrammetric base, focal length and the measurement precision equal to two pixels; 


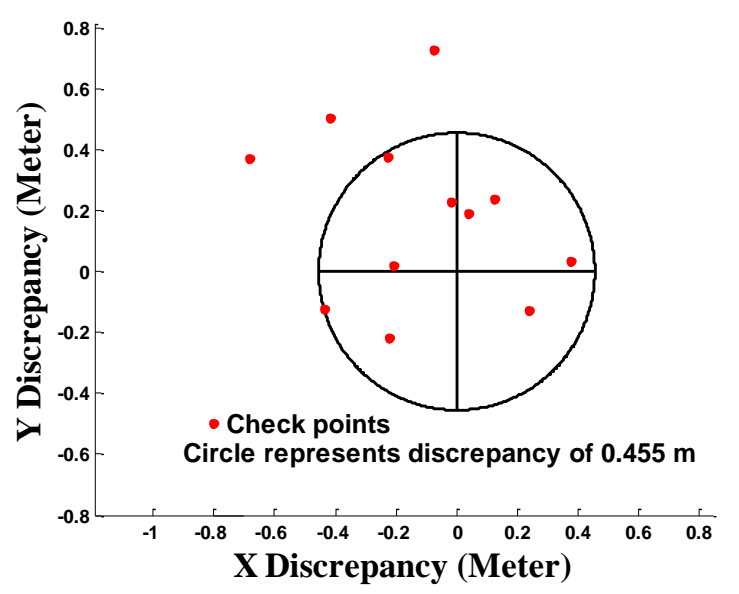

Figure 10 planimetric discrepancies on verification points of the region`s orthoimage

- The autonomous procedure in LPS software, based on digital correlation, allowed the generation of a DSM for the studied area. The manual filtering, based in stereoscopic view, to select only ground points to generate the DTM, achieved vertical accuracy nearly to $1.6 \mathrm{~m}$. This vertical accuracy was computed by analysis of vertical discrepancies of the 12 checkpoints;

- In the whole orthoimage, horizontal accuracy was close to $0.455 \mathrm{~m}$. This value was obtained from the analysis of planimetric discrepancies in 12 checkpoints. As it was expected, the value was approximately equal to the value of the horizontal accuracy resulted in aerial triangulation of the image block.

Future research on this topic will focus on developing methods to increase the accuracy of the direct determination of the image`s exterior orientation parameters and use them in the aerial triangulation procedure in order to decrease the number of used control points on the block.

\section{ACKNOWLEDGMENTS}

We would like to thank the two Brazilian governmental agencies $\mathrm{CNPq}$ (The National Council for Scientific and Technologic Development) and CAPES (The Coordinating Agency for Advanced Training of High-Level Personnel) for their financial support in this research and SIMEPAR (Technologic Institute Simepar) to provide the necessaries material to develop this study.

\section{REFERENCES}

Colomina, I., Molina, P., 2014. Unmaned Aerial Systems for Photogrammetry and Remote Sensing: A Review - ISPRS Journal of Photogrammetry and Remote Sensing 92, pp. 79-97

Darwin, N., HAMID, N.F.A., Udin, W.S., MoHD, N.A.B., 2013. Light Weight Rotatory-Wing UAV for large scale mapping applications. Asia Geospatial Forum, Kuala Lumpur, Malaysia, pp. 24-26.

EISENBEISS, H., 2009. UAV Photogrammetry, PhD Dissertation, Institute of Geodesy and Photogrammetry, ETH Zurich, Switzerland, Mitteilungen N.105, p. 235pages.
EISEnBEISS, H., 2011. The Potential of Unmanned Aerial Vehicles for Mapping, in: Fritsch/Spiller (eds.): Photogrammetric Week 2011, Wichmann Verlag, Heidelberg, pp. 135-145.

EVERAERTS, J., 2008. The use of Unmanned Aerial Vehicles (UAVS) for remote sensing and mapping. International Archives of the Photogrammetry, Remote Sensing and Spatial Information Sciences XXXVII (B1), 1187-1192.

GÜLCH, E., 2012. Photogrammetric measurements in fixed wing UAV imagery International Archives of the Photogrammetry, Remote Sensing and Spatial Information Sciences VolumeXXXIX-B1,2012 XXII ISPRS Congress, Melbourne, Australia.

Jorge, C., Inamasu Y., Carmo, B., 2011. Desenvolvimento de um VANT totalmente configurado para aplicações em Agricultura de Precisão no Brasil, Anais XV Simpósio Brasileiro de Sensoriamento Remoto - SBSR, INPE, Curitiba, PR, 399 406

Khan, A., Schaefer, D., TaO, L., Miller, D., Sun, K., Zondlo, M., Harrison, W., Roscoe, B., Lary, D., 2012. Low Power Greenhouse Gas Sensors for Unmanned Aerial Vehicles. Remote Sensing, 4, 1355-1368.

Laliberte, A., Goforth, M., Steele, C., Rango, A., 2011. Multispectral Remote Sensing from Unmanned Aircraft: Image Processing Workflows and applications for Rangeland Environments. Remote Sensing, 3, 2529-2551.

LONGHITANO, ALFREDO, 2010. VANTs para sensoriamento remoto: Aplicabilidade na avaliação e monitoramento de impactos ambientais causados por acidentes com cargas perigosas. Dissertação (Mestrado) - Escola Politécnica da Universidade de São Paulo. São Paulo.

Turner, D., Lucieer, A., Watson, C., 2012. An automated technique for generating georectified mosaics from ultra-high resolution unmanned aerial vehicle (UAV) imagery, based on structure from motion (SfM) point clouds, Remote Sensing, 4, pp. 1392-1410 